John Burgess, Lindy Henderson, Glenda Strachan*

\title{
Women Workers in Male Dominated Industrial Manufacturing Organisations: Contrasting Workplace Case Studies from Australia
}

This study compared women's roles, expectations and experiences in two comparable, male dominated industrial manufacturing companies in Australia. Both organisations are subject to legislated equal opportunity program and reporting requirements. The research was conducted to examinee the differences between what is submitted in their EEO reports and the experience of women workers in the organisations. Good jobs and poor jobs existed in the same legislative and industrial framework and in the same local labour market. The differences are located in a combination of organisational and cultural conditions.

Key words: Equal Employment Opportunity, Job Quality, Human Resources Management, Workplace Culture

* Dr. John Burgess \& Lindy Henderson, Employment Studies Centre, University of Newcastle, Callaghan NSW 2308, Australia. Phone ++61 2 492150281, fax ++61 2 49216911, e-mail john.burgess@newcastle.edu.au.

Professor Glenda Strachan, School of Management, Griffith University, Nathan, Queensland 4111, Australia, e-mail: g.strachan@griffith.edu.au.

** Article received: April 30, 2005

Revised version accepted after double blind review: September 20, 2005. 


\section{Introduction}

A slow decline in gender segregation over the last twenty years has been demonstrated in the USA and Australia (as elsewhere) but women still predominate in sales and service occupations, and men in skilled trades. The growth of women's overall representation in management and professional occupations has increased, especially in female dominated organisations, but segregation at the workplace level remained almost unchanged, despite nearly two decades of equal opportunity legislation (Watts 2002).

Officially, equal employment opportunity for women is enshrined in Australiawide legislation and is reflected in industrial awards and agreements. The original EEO legislation (Affirmative Action (Equal Opportunity for Women) Act 1986) emphasised the need for positive programs to redress disadvantage, later legislation (Equal Opportunity for Women in the Workplace Act 1999) is more general in its statements about what should be done within organisations. The Equal Opportunity for Women Agency (EOWA) that is responsible for administering the Act provides guidelines for the preparation of programs and reports, and collects and publishes reports from larger non-government employers annually. The EOWA requires that each organisation with over 100 employees prepare a workplace profile and address each of six equity areas in an annual report unless waived from doing by submitting a series of satisfactory reports. The equity areas are sexual harassment, pay equity, training and career development, work/life balance, recruitment/promotion/separation, and occupational segregation. Penalties for non-compliance are weak. Employers may also apply to be named as an Employee of Choice for Women and can use this accolade in recruiting or marketing. EOWA has adopted a pragmatic approach towards implementing EEO principles that privileges the business case for EEO but also recognises fair and equal treatment for the individual as an ideal. The legislation is supported by anti-discrimination legislation operating in both the Federal and State jurisdictions.

The EEO legislation and mandatory reports require that, at a minimum, employees suffer no discrimination on the grounds of their sex. Further, the EOWA emphasises the business case for improving women's working lives: 'Employers are reaping the benefits of their equal opportunity for women in the workplace programs through increased employee effectiveness, attracting and retaining the best talent, improved morale and increased consumer and market responsiveness. (EOWA 2005). Thus, good jobs for women are also promoted as good for the bottom line of business. This paper investigates the way in which legislation and reporting promote EEO for women and how this is corroborated by women's reported workplace experience.

In this research two organisations (C1 and C2) in a traditional male employment sector (manufacturing), demonstrated dramatic differences with respect to the conditions and quality of work available to women employees. The most marked of these was the relative number of women in management roles and the availability of flexible employment conditions for women workers. Both organisations are strongly dominated by male employees at all roles and levels except as office workers, but in C1 a much greater proportion of the female workforce was in management. The second major difference was that in one organisation (C1), women felt accepted and comfortable at work, and considered that they had adequate access to training, promotion and 
improving working conditions. At the other (C2) women considered themselves undervalued, marginalised, ignored or even ostracised, had no expectations of having opportunities for career development and were dissatisfied or unhappy at work. What struck the researchers is how the experience of women's working lives can be so different in similar industries in the same local labour market. What explains these substantive differences in the experience at work, and ultimately, in the perceived quality of work?

The paper will review the research questions and then discuss the research methodology. The analysis then reviews the findings from the documentary evidence and from the case study interviews. Explanations for the differences between the two case studies are then undertaken and the conclusions are set out.

\section{The research questions}

The research is set within a broader context of examining the processes, participation and responses of female employees to EEO programs. The issue of the quality of working life is a derivative of this broader research agenda that involves documentary and case study analysis of organisations subject to EEO reporting requirements in Australia across a range of industries and in different locations. EEO programs are supposed to improve the opportunities for women workers, reduce barriers to satisfying working lives and improve the quality of their work experience (EOWA 2005). In addition to looking at official documents within and extraneous to the company, examining the implementation and effectiveness of EEO programs in organisations also involves female workers reflecting upon their opportunities to advance, to balance work and family needs and to have a fruitful work experience. In this article two contrasting case studies are reported. An examination of the experiences of the women workers at the two plants involves an assessment of the effectiveness or failure of their EEO programs.

In the context of job quality the research did not set out to provide objective measures or indicators of job quality between organisations since any formal assessment of job quality faces conceptual, measurement and evaluative problems. What makes a good job? What do workers expect in their job? How do we separate the ideal from the reality? In some cases job quality is asserted through reference to a set of attributes (Hunter 2000) and in other cases the discussion is about "bad" jobs, generally through reference to the pay distribution (Lewis 2002; Whitehouse/Frino 2003; Whitehouse 2003). In addition to the problems of conceptualising job quality, we also confront the usual problems associated with labour analysis. Are we discussing the attributes of the job? Are we discussing the people who perform the job? Are we discussing the context in which the job is carried out? Job quality encompasses all of these aspects and as such it makes the task of analysis difficult.

Job quality can therefore include pay, worker satisfaction and relationships between employees and between managers and employees. That is we can assess job quality in terms of the work performed, the individual performing the job, the workplace at which the job is carried out and the organisation in which the workplace is located. In this research we first examined public documents (official reports and industrial instruments) of selected enterprises and then asked some of their employees to 
describe their work experiences, to tell us about their ambitions and aspirations, whether they thought that these would be fulfilled, and whether they were satisfied with their jobs. The quality of working life is subjective, relational and embodies formal policies and procedures, as well as informal arrangements within the workplace. In this instance the quality of work is embedded in the experiences of these working women and incorporates objective as well as subjective conditions of work. The respondents discussed both formal and informal structures within their workplaces which made for, or denied, a satisfying work experience for women.

The key research question is: What makes a "good" job and a "bad" job in a very similar institutional environment for a group of minority workers? Why did female workers at one workplace feel valued, informed and respected; but at the other workplace marginalised and ostracized? On the surface, their work environments appear similar, but the experiences they reported were very different.

\section{Women in male dominated organisations}

The literature highlights some issues faced by female workers in traditionally male dominated industries. Dainty et al (2001) in a UK study of the male-dominated construction industry found that women employees had lower levels of advancement and a higher turnover in comparison to men. 'Many male informants stated openly that construction is only a viable career option for people who could accept its working practices and culture' (Dainty et al 2001: 302) A 'male' orientation characterised by full-time work, vertical career progression and career centrality, tended to support 'a workplace culture of inflexibility and discrimination' (303-4)) in which women struggled to succeed, or chose to move out into more accommodating industry sectors. They found that male employees' chief concern was with career advancement and maintaining the existing work environment, which already suited them, whereas 'women were concerned with developing an equitable and flexible work environment with the opportunity to combine their work and family lives' (304). Women also wanted more transparency and openness in promotional procedures. The desire for individualised career paths and training plans was shared by men and women. Do these findings have resonance in a different country and in a different legislative context?

In Australia, managerial attitudes have been shown to be key determinants of work-family practices for women workers (Bardoel 2003). Along with other aspects of the workplace, she distinguished between formal policies and practices that were integral to work arrangements within the organisation and supported equal opportunity. The attitudes of managers were found to be central to an organisation's responsiveness to work-family needs. Although she found that no one theoretical model prevailed, the role of top management was critical 'in shaping and supporting a work environment that accommodates work-family needs of employees' (Bardoel 2003: 17). The role of front-line managers in supporting work-family policies, whether at a formal policy level or by way of informal arrangements has been demonstrated. (Christensen/Staines 1990). Several studies have found that job satisfaction is higher and work-family conflict is reduced where supervisors are supportive of work-family balance (Burgess/Strachan 2005; Batt/Valcour 2003). 
Organisational differences also shape women employee's experiences (Belle 2002). Her comparison of two contrasting employers in related industries (electricity and electronics) where women employees were in the minority offers an alternative way of looking at women's opportunities in male-dominated industries. Women working in one organisation, which had a technical-focussed, hierarchical management structure, had poorer career prospects, but more acceptable working hours. In the other, women had better career prospects but were expected to take on a greater workload. Belle found that women and men expected the same treatment as each other in both organisations.. In neither organisation were women found in the top echelons of management. Women limited their ambitions either because they could see almost no chance of progression to the most senior jobs, or because they could not balance work and family needs( Liff 1997; Dainty et al 2001; French 2005). This last point gives conditional confirmation for Hakim's view that a group of women workers choose to subordinate their roles in the market economy to non-market activities such as child rearing and are often among the ranks of the part time and casual workforce (Hakim 1998; Batt/Valcour 2003) whereas the present study shows that such choices may not exist.

Organisational structures and managerial attitudes have implications for the quality of women's jobs. They reflect the experiences of women in different legislative and industrial contexts but focus on factors within the organisation. That is, despite legislative and labour market conditions differing, managerial practice and organisational structures are important in shaping the opportunities and experiences of women in male dominated workplaces.

\section{Research methods}

As part of a larger project designed to examine the mechanisms by which EEO policies are developed, implemented, evaluated, reviewed and modified, two organisations with predominantly male workforces were studied. The research involved the examination of documentary information in the form of EOWA reports and other documents prepared by the organisations which highlighted the employment equity issues that each had chosen to emphasise. Wages and conditions set out in Enterprise Agreements and Awards (both industrial instruments) were examined. In addition to this documentary evidence, the researchers conducted semi-structured interviews with a number of employees at a variety of levels of responsibility, as well as with representatives from management (usually line mangers) and the manager responsible for equal opportunity (usually the HR manager). At C1, seven employees, five of them women, were interviewed. At C2, fourteen employees were interviewed, including eight women. Managers were interviewed individually, female employees were interviewed in a focus group. The interviews were semi structured and typically lasted for 30 minutes for individuals up to 90 minutes for the focus group of employees. The taped interviews were transcribed and the data coded using QSR NUD*IST software. In the subsequent discussion we examine what the documentary evidence reveals and then compare this with the experiences of women at each of the workplaces. 


\section{The organisations}

C1 is owned by a multinational consortium, C2 is an unlisted Australian company. Both companies are heavily export orientated. Both are situated within one kilometre of each other on the outskirts of a major regional centre with a population of around half a million people. They are located in similar industries and within the same local labour market. The unemployment rate at the time of the survey within this labour market was around 9 per cent, well above the national average of 5.5 per cent. The regional labour market generally has higher rates of unemployment and lower rates of labour market participation (for both men and women) than the national average.

The workplace profile (Table 1) demonstrates that both workplaces are male dominated, that females are largely occupationally segregated within the workplaces and are located at the sub-managerial grades. The major difference between the profiles of the two organisations is the higher female employment density in company 2 (C2) and the higher female managerial density in company 1 (C1).

Table 1: Workplace Profiles for the Two Case Study Organisations

(Source: Derived from EOWA reports, C1 and C2, public domain, EOWA website)

\begin{tabular}{|l|c|c|}
\hline & Company 1 (C1) & Company 2 (C2) \\
\hline Total employees & 1000 & 335 \\
\hline Females & $55(5 \%)$ & $46(14 \%)$ \\
\hline Female managers & $17(17 \%)$ & $1(5.5 \%)$ \\
\hline Female apprentices & 1 & 1 \\
\hline Female engineers & 1 & 0 \\
\hline Female clerical, admin & $15(83 \%)$ & $34(47 \%)$ \\
\hline
\end{tabular}

\section{EEO legislation, industrial agreements and good jobs and bad jobs: The documentary analysis}

The impost of anti-discrimination legislation was acknowledged in the industrial instruments of both, in their public reports to EOWA and in their official policies. C1 states in its EEO policy that it 'believes all employees should be treated with respect and fairness' (EOWA 2005) This echoes the words of the EOWA itself and suggests an emphasis on protecting the individual employee from unfair or discriminatory treatment. The words 'respecting and valuing the diversity of the workforce by helping to prevent and eliminate discrimination' are included in its industrial instrument (Clerical and Administrative Employees Award 2002). C2 is more circumspect in its statement that 'the employer is committed to a policy of non-discrimination' and 'employees will be treated equally, irrespective of sex ...' (www.wagenet.gov.au 2005). Liff (1997) would regard this as seeking to 'dissolve differences' but in the context of C2 perhaps 'ignoring differences' would be more apt.

In making annual reports to EOWA, organisations are required to 'identify the issues for women' by consulting with employees, then prioritise and address those issues, evaluate the effectiveness of their actions and describe their plans for the next year. Both organisations had submitted reports for the year 2003-4. The quality of fact-finding and analysis differed substantially, with $\mathrm{C} 1$ conducting a plant wide em- 
ployee survey, employing a variety of other (quite elaborate) consultative processes, referring to workplace committees and auditing existing policies and practices, among other measures. Areas of concern related to harassment, display of sexually explicit material, provision of appropriate equipment and the development of career paths for female managers. From the documentary evidence available from EEO reports it was clear that $\mathrm{C} 1$ engaged in a comprehensive and extensive review and evaluation process of workforce gender issues and policies.

C2 had fewer resources with which to collect and collate information, and relied mainly on looking at staff profiles and 'informal monitoring'. This reflected the fact that its HR section was small: it comprised one part-time female manager who, while committed to EEO principles, could not support this commitment through program development and evaluation. C1 was able to furnish long and complex responses to each employment matter, and to detail achievements and future aims. Both companies recognised the need to continue to offer training in the principles of EEO and antidiscrimination to managers and supervisors. The display of inappropriate material, the need to provide networked computers for employees on parental leave and the supply of suitably sized personal protective equipment for women were priorities at $\mathrm{C} 1$, as was addressing the current limited scope for women to advance in the company. C2 prioritised reducing the segregation of the workforce through recruitment, a Herculean task in its labour market, but while C1's managers were concerned about low levels of recruitment of women into non-traditional areas, this came well down their list of priorities.

While the reports were accurate in themselves (not falsified), one was obviously more thorough and more fully resourced than the other. Employees had been consulted in the ways set out in the reports, and the priority areas were being addressed.. In summary there were clear differences between the documents supplied by both organisations to the EOWA. C1 was thorough in terms of EEO program development, design and evaluation, and the process was resourced. In contrast for $\mathrm{C} 2$ the process was rudimentary and under resourced. The reports themselves are indicative of different levels of active commitment to EEO programs between the two organisations, or perhaps to a poor understanding of how to identify and address relevant issues.

\section{The contrasting experiences of female workers in the two case study companies: Evidence from the interviews}

In this section the different experiences of women workers within the organisations are contrasted. Where possible the women workers tell their stories and share their experience.

Do the reports submitted to EOWA reflect the experience of employees? The experience of women at one of the workplaces was at odds with the statements found in the official documentation, but in broad agreement at the other. At C2.one woman reported being chastised for swearing unlike male colleagues around her, and others commented that they did not have equal access to a lunch room because male employees objected to their presence there. There was a perceived differential in access to training and promotion opportunities. In making arrangements for occasional leave (for instance to attend to a personal matter) male employees at C2 expressed sat- 
isfaction in being able to negotiate 'a few hours off with their supervisor, while women employees complained that such arrangements were impossible to make as their requests were routinely turned down. Moreover, they perceived this as discrimination on the basis of sex and felt powerless to take action to redress the situation. By contrast, there were no such complaints of overt or covert discrimination at C1.

A lack of adequate consultation with women employees in formulating and evaluating policies was strikingly evident in talking with women at C2. They reported that there was no opportunity for them to raise issues of relevance to them, and their priorities of access to training, career development, harassment and bullying, and flexible work arrangements had not been considered. In the words of one longstanding employee: 'You make the same comments each year, and no one is listening, and you can say the same thing year after year'. The HR manager, on the other hand, considered that women had not raised any issues that required to be addressed.

In $\mathrm{C} 1$ the experience of the women was one of a non discriminatory workplace. In $\mathrm{C} 2$ the experience was of a discriminatory workplace. Both organisations gave strong support to a non discriminatory workplace through their annual EEO returns.

\section{Did the collective agreement promote and codify EEO practices and programs?}

In the case of both organisations the workplace agreement was not an instrument that incorporated progressive EEO programs nor did it codify such programs. The major trade unions largely represented the interests of the more numerous and predominantly male trades workers and it was their concerns that trade unions articulated. The segregation of the workforce at each plant, especially in C2, resulted in the female clerical workers being non unionised and being covered by a common law award (there was no collective agreement for this group of workers). Overall trade unions and workplace agreements were not important in promoting EEO.

\section{Are attempts to improve employment conditions and opportunities for women employees suc- ceeding?}

C1, the larger workplace, has been able to provide more opportunities for women to develop careers or obtain new skills. Several women interviewed had occupied different roles, had transferred between departments and between part time and full time work over the years Some had returned to work part time after taking maternity leave, and had later returned to full time work or taken on special projects which enabled flexible working arrangements. Women at $\mathrm{C} 1$ told us that they are encouraged to take on new roles and are actively considered in succession planning. This was echoed in statements by the HR manager.

Flexible work arrangements are difficult to sustain in the face of 12 hour shifts and continuous rosters and this was so at both workplaces. One mother said of her time as a shiftworker in the plant, that the combining of work and family was 'very, very, difficult. If I had the same choices again, would I do it? Probably not.' So even in the one workplace, there are good jobs and not so good ones. The HR manager and female workers agreed that an effort was made to strive for a balance between work and family. Paid maternity leave of six weeks can, for instance be followed by a grad- 
ual return to work, and opportunities exist for flexible and varied work roles, and women at $\mathrm{C} 1$ have choices:.

'A lot of people asked me what I was going to do. Even my manager. So, there was quite a lot of - he was very consultative— like he actually wanted to know my views on what I wanted to do, rather than imposing any on me' (unit manager).

'I came back two days a week when they were five months and then three days a week when they were one year. And then four days a week when they were about eighteen months, then full-time when they were two. So, I had a staggered increase, which was fabulous. The organisation supported it.' (mother of twins, strategic workforce planning project).

'I was on maternity leave when I was here but only for a few months. Then I did parttime for twelve months but the last few years I changed down to a four day week and shorter, doing school hours only. Then I increased it doing a project for the next twelve months, so I am back here full-time, at the moment' (Payroll clerk).

By contrast, there were few if any opportunities for these supportive working arrangements at $\mathrm{C} 2$. Of the interview sample, some had returned to full time work from maternity leave but apparently others had chosen to leave the company. The researchers were told that management refused to entertain the idea of part time work or flexible hours. As one office worker explained it 'You work 40 hours, you get paid for 40 hours, there is no flexibility at all'. Among those interviewed, a significant level of discontent was expressed loudly and willingly. Issues mentioned included lack of career paths, poor and inconsistent access to training courses, and lack of information about job opportunities within the organisation. There is no part time work, no jobshare, strict rules about maternity leave, and no family-friendly workplace policies. A draftsperson had recently been offered training, and there were two female trainees in the accounts department, but overall, there are no significant attempts to improve employment conditions for women in $\mathrm{C} 2$. Asked why women leave the company, one replied:

'It is a combination of different things. There are some people want to work part time for different reasons and that is not available, so they leave. There are other people who leave for the money, others leave because they don't get any job satisfaction, they are just not getting anywhere and they've just had enough or there is disharmony within their department. So they just get tired of that'.

The women employed at C2 considered that they had 'bad jobs'. Moreover, they held out little hope that their jobs would get better. When asked, they suggested that they remained working at $\mathrm{C} 2$ mostly because there were few other jobs available locally, but they would leave if opportunities became available elsewhere. In contrast, the women at C1 had 'good jobs' because they had information, they were supported by management programs, had opportunity for advancement and some control over their working lives. They intended to stay with the company, and they were not searching for vacancies elsewhere.

While a larger organization may have more roles that can be filled on a part-time basis, and more flexibility in accommodating different work arrangements, management attitudes played a large part in the way jobs were constructed in the two organisations. At C1, the human resources manager was enthusiastic about the contribution women could make, especially as team members and team leaders: 
'I think that diversity must help the organisation and does. I can see a male over in the Cast House, sitting down with his group of twenty three males and being adversaries. But if I put a female leader into that environment-not saying that she would be able to get different outcomes-but I generally believe that they can'.

He valued diversity among employees and was ready to embrace change within the organisation. This was in marked contrast to C2 which closely fitted the pattern described by Dainty et al (2001), of an inflexible and discriminatory workplace oriented to the preferences of men for a rigid vertical career structure.

\section{What Opportunities are there for training and career development?}

Some women at $\mathrm{C} 1 \mathrm{had}$ attended training courses provided by the company, taken time off to pursue further education, or had recently attended TAFE (technical college) or university, with the company paying fees and/or providing extra leave to enable this, and others had undertaken computer courses or further training, also at company time or expense and they expressed satisfaction about this. This was not the case at $\mathrm{C} 2$. A female draftsman had been offered training at TAFE, but this seemed a rare departure from the usual policy.

One problem there seemed to be inconsistency of access to further training. These comments were made by office workers at C2:

'Things are different for different people. That annoys me a lot too. Some people get some things and some people just stay at the bottom' (office administrator).

'I have a manager I used to have when I did all my appraisals, all I asked was to do an Excel course to further my knowledge in Excel. He would say no every time. Then I found out another girl who worked here in another office only worked here six months and she is doing all these courses, that is worth thousands, and I have been here eight years'. (clerk, accounts department).

Interestingly, several women at C2 were undertaking courses on their own account, outside work hours. Their explanation was that this would enable them to leave C2. These women were committed to careers and were seeking advancement, but not with their current employer. Frustration at the lack of opportunity for career development was expressed by this office worker: 'A few years ago, there was myself and another lady who has since left, and we were told by the then general manager, that there were no career paths for females'. (office worker with 15 years service).

\section{Occupational segregation}

Both organisations have sought to recruit women into non-traditional areas, but have met with limited success. Few young women apply for apprenticeships or, until very recently, enroll as engineering undergraduates in university programs. Some of the work is heavy, dirty, hot, and arduous and not attractive to much of the female workforce. C1 has made efforts to provide women with a safe working environment and access to career advancement, and has secured several women places in management areas. $\mathrm{C} 1$ noted in its EOWA report a concern that career paths for women were still somewhat restricted. The research indicated that, by comparison with $\mathrm{C} 2$, women were already well placed in the organisation, and were seeking to change or better their roles. 
For C2, eliminating occupational segregation was a priority area. Recruiting women into non-traditional areas of work was important for the prestige of the organisation and for individual section managers, reflecting official company policy, if not practice. Women in non-traditional areas are few, and do not necessarily find the welcome mat in place. 'When I first started here, my foreman told me that women shouldn't be working in this industry.' (woman worker, manual trades). In short, the intention was not matched by the practice. There were no career paths available to women in the clerical area, and those in the production area had to contend with a hostile workplace.

\section{What opportunities are there for managing work/ life balance?}

The starkest contrast between the two organisations was in the ability to strive for, and achieve, an appropriate work/life balance. Parental leave, ease of access to carers' leave (whether planned or in an emergency), the ability to attend to some personal matters in business hours, and respect for employees' lives outside work are crucial in determining the quality of the job for many women workers (Burgess/Strachan 2005; (Hyman/Summers 2004)). Part time or job share, flexible working hours, and the opportunity to transfer between part time and full time work as family needs dictated, was a source of praise among employees in $\mathrm{C} 1$ and disgust in $\mathrm{C} 2$.

The HR manager at C1 reported that the company tried to ensure a good work/life balance for employees, and the women interviewed confirmed this. Shift work and continuous rosters were limiting factors at both workplaces, in the words of one manager at C1, but 'they do all they can'. Employees saw the recent introduction of six weeks' paid maternity leave as evidence that the company valued family life, but long-standing employees also reflected on flexible work arrangements that had been tailor-made for them. Moreover, workers' individual needs were usually respected.

Part-time work was not generally available at $\mathrm{C} 2$ and women were angry that they could not take even a few hours away from work without penalty to attend to family matters. Male workers, on the other hand, indicated that they could usually negotiate some flexibility by making informal arrangements with their supervisor (see Eason 2003). Given that $29 \%$ of employees of $C 2$ who had left the company in the last year, were women, double the average turnover rate, the research probably missed the most disgruntled workers - they had already gone. The experience in C2 is surprising, since the Australian norm for balancing work and family responsibilities is through parttime work, with Australia having one of the highest part-time employment shares across the OECD (Pocock 2003; Bittman/Rice 2002). A female factory worker told us:

'I don't understand why they are so anti- part time in the first place. There was a girl who did my job and she was willing to come back part time, yet they paid my airfare, all my furniture was moved from Perth to here, because I said I would go full time'.

Maintaining a work/life balance was not a gender issue at C1: 'We have a lot of males in the workforce that are single dads, or relationships have broken down, where we have to be flexible with their working hours, which is difficult when they work the kind of rosters that they do'. (female manager, C1). 
In contrast, a manager at $\mathrm{C} 2$ thought that child care was predominantly a women's issue. Asked about child care in the area, a male manager admitted that this was not an issue he had considered: 'One, it hasn't been an issue, two, I don't have that problem from a personal point of view, I've never had to look around and see. But I don't know whether there are or not.'

It is puzzling that although both plants are located almost side by side in an industrial park, and hence the accessibility of shops, schools and other services is identical, employees at one workplace, C2, considered themselves isolated with poor access to these services, while those at $\mathrm{C} 1$ did not mention this as a difficulty. It might be the case that in a workplace plagued by dissatisfaction and low morale, employees find more aspects of the workplace distasteful and are more inclined to attribute their unhappiness to it. The HR manager at C2 had some insight into her situation::

'The thing that keeps coming back is we are not perceived to be family friendly. That is the thing that keeps coming back. We don't have the flexibility that is offered in other industries. Part of that comes to the fact that we are in the engineering business and that is what we do. But this should not be an excuse for not having policies'.

This comment is revealing. Firstly, it demonstrates that the HR manager sees the problem for women workers, but has not been able to institute change. EEO policies are stated in reports to EOWA and in industrial instruments, but this is not translated into practical policies (Eaton 2003). Clearly, being an 'engineering business' is seen within the organization as sufficient justification for its approach to work and career, and one where women's work is marginalized or even denigrated. The critical role of senior management (Bardoel 2003) and line supervisors (Eason 2003) in supporting flexible work practices is confirmed in these case studies.

For C2, eliminating occupational segregation was a priority area. Recruiting women into non-traditional areas of work was important for the prestige of the organisation and for individual section managers, reflecting official company policy, if not practice. Women in non-traditional areas are few, and do not necessarily find the welcome mat in place. When I first started here, my foreman told me that women shouldn't be working in this industry' (woman, manual trades). In short, the intention was not matched by the practice. There were no career paths available to women in the clerical area, and those in the production area had to contend with a hostile workplace.

\section{Process of recruitment/promotion/separation}

It has already been noted that recruitment and promotion present difficulties for these male dominated, technically focussed organisations. Both have undertaken similar measures to attract females into apprenticeships or at graduate level, with limited success. Where recruiting women for non-traditional roles is a stated priority at C2, C1 has placed more emphasis on developing careers for the women it already employs. That $\mathrm{C} 1$ has used its recent restructuring to position more women in management roles, but a similar opportunity has been lost at C2, is best explained by the culture of the organisations and the kind of expertise managers are seen to need. C1 embraces diversity and values the different inputs of men and women to problem solving or management. Opportunities for promotion are partly a function of size, but also re- 
flect a more imaginative and inclusive attitude to management. However, C2 has so far only promoted professional engineers to management roles, thus limiting the chances of women progressing to management.

At $\mathrm{C} 1$, the HR manager commented that women in the workplace were more often ready to take on further training leading to increased responsibility: ...

What I find interesting is that those females that have done that [worked as plant operatives], nearly $100 \%$ of them have gravitated towards leadership roles very easily. And it's like, now that I understand that, okay, I'd like to move on, where I tend to see a lot of guys who want to come and do their grunt work and then go home.'

\section{The Construction of Good Jobs and Bad Jobs in the Two Case Studies}

What explains the very different experiences of women workers in the two case study organisations? There were dramatic differences between the two organisations with respect to conditions and quality of work available to women employees. These material differences were implicit from the differences in detail and policy development contained in the EOWA reports and were confirmed in the interviews with women employees in the two organisiations. Both complied with the letter of the EEO legislation and both had formal policies of equality; but workplace organization, management style and company culture were more potent determinants of women's experience as workers. It is clear that formal EEO procedures, anti-discrimination legislation and a commitment by management to EEO are not in themselves sufficient to realise EEO goals or attract women workers into organisations. The management and workplace organisation, together with the commitment to EEO in practice differed significantly between the workplaces. We will highlight what appeared to be important factors explaining the difference in the working experiences of women in the two organisations:

What factors determine the experience of the job? There are obvious material or objective factors including access to training, flexible working arrangements, career opportunities and flexible leave arrangements. There were major differences between $\mathrm{C} 1$ and $\mathrm{C} 2$. However, the subjective experience did also differ across the workplace. This was associated with the construction of "women's work", attitudes of supervisors and managers towards women workers and the gendered construction regarding commitment and career development. Both were masculine organisations in terms of workforce and workplace profile, yet there were attempts by management at $\mathrm{C} 1$ to open up the workplace to women and to accommodate and retain women workers. No such accommodation or encouragement was present at C2. EEO policies and programs were integrated into the corporate management plan of $\mathrm{C} 1$. The overall management plan included EEO dimensions for corporate development. In C2 there was no such attempt to actively integrate EEO into the formal corporate strategy.

Women felt valued in $\mathrm{C} 1$. They were able to vary working time arrangements and integrate work and family responsibilities, but no such flexibility was available in C2. In $\mathrm{C} 1 \mathrm{a}$ policy of promoting from within the existing workforce provides career paths for some, while others have the chance to work on special projects and to widen their skill base. Workers are able to transfer between part time and full time work, allowing women to accommodate to changing family needs. Women were offered active op- 
portunities to upgrade skills and undertake career advancement in C1, once again in C2 the opportunities for training and skill upgrades were very limited. Both organisations are male dominated workplaces, both organisations profess to wish to increase the female employment density. However, at C2 females largely remain segregated in the clerical area and do not feel welcome in production areas of the plant. A very different "atmosphere" was present in C1.

In both organisations the need for support for EEO policies at the level of senior management was affirmed, and both regarded senior management as promoting EEO. This stands in the face of markedly different practice outcomes between the organisations. Bardoel (2003) found that institutional factors and managerial choices influenced the adoption of family-friendly workplaces, while Dainty et al (2001) found women advanced in 'male-oriented' workplaces only if they conformed to prevailing work practices and culture. Eason (2003) stressed the importance of informal practices and the crucial role of line managers. These conclusions are relevant to $\mathrm{C} 2$ where the underlying workplace culture is masculine and women remain segregated from the production areas of the plant. There were relatively few attempts to inform and educate managers and team leaders regarding EEO programs.

What explains the differences in the objective and subjective conditions of work for women? It is not due to differences in industry, institutional conditions, competitive conditions, union activism, gender workforce composition or workforce location. These were the same for both workplaces, yet the outcomes are very different. Clear differences were present with respect to managerial commitment (Bardoel 2003) at each workplace and workplace culture (Townsend 2005) at each workplace. Also, women at C2 did not comply with a male norm about what is a "job" (Dainty et al 2001). At C2 a job was still regarded as full-time, ongoing and production centred, with no deviations from this norm considered Even for clerical workers), despite the company having an ongoing EEO plan. At C1 differences from this norm were facilitated and accommodated within the organisation for all occupations.

At C1, the HR manager and other managers, several of them women, value the difference that women can make to the workplace. They see diversity as a positive aspect of the workplace and recognise difference. Moreover the organisation has been at pains to provide opportunities for women at different stages of their working lives. This is far from the case at C2. Can organisational culture explain some or all of the differences between the two organisations in this study? As Townsend $(2005,97)$ notes: Within an organisation culture provides employees with an expectation of what will happen and how they should behave...'

Workplace culture was found to be an important factor that determined the expectations and opportunities available to female British workers in a series of workplace case studies of call centres conducted by Durbin (2006).

Culture summarises what a worker feels about the organisation and their place within the organisation. Clearly, the culture of C1 and C2 were very different. C2 follows a policy that is closely allied with complying with legislation and superficially offering equal treatment for male and female employees. C1 has espoused a Managing Diversity approach, in which the need to comply is recognised, but a culture of recog- 
nising and valuing differences is just as important. In the research of which these case studies form a part some of the organisations, including C1, displayed a blurring of barriers between implementing EEO for women and Managing Diversity. This supports the proposition that managing diversity policies would be grafted on to preexisting EEO policies (Strachan/Burgess/Sullivan 2004). In recognising the business case for EEO C1 has full time HR professionals who are able to present a business case, develop and implement policies, and educate managers and workers within the workplace. Culture is matched by managerial commitment.

One organisation welcomed diversity in management styles and valued differences in addition to avoiding risks to the organisation (prosecution or adverse publicity) of non-compliance with the legislation. At $\mathrm{C} 1$, considerable resources had been put into staff development, and the company wanted to retain its workers. The organisation boasts of a high level of training opportunities for their very small female workforce, and has succession plans which encourage women. Lack of flexibility, opportunity and work/life balance was seen by management as a source of absenteeism or dissatisfaction (Burgess/Strachan 2005). Thus the metals processor recognised a business case for EEO which was consistent with but in addition to legislative and reporting requirements and was both willing and able to remove many barriers to equal opportunity for women.

Commitment to EEO by management at $\mathrm{C} 2$ was not evident during the interviews and the situation was exacerbated by a poorly resourced HR department and a failure to set achievable goals in terms of women's career choices. Female employees of $\mathrm{C} 2$, related that there was little scope for advancement or promotion, and limited opportunities for further training within the existing company structure. Since the managers are almost all professional engineers, the composition of the labour market as a whole, as well as the employment profile of the workplace, mitigates against women achieving senior roles. Women are not provided with equal opportunities to attend training courses or for advancement. The insistence that women returning from maternity leave (a statutory 12 months, unpaid) to full time work, fails to recognise family demands or individual choice. There is little place for flexibility in this organisation, simply because, in the words of one manager, 'Yeah, it's industry'.

At C1, HR professionals and senior management have set clear, realistic goals in seeking to recruit, retain and promote its small female workforce. While legislation and the reporting process might mediate this, the approach is based on a model that embraces diversity and values difference (Liff 1997). C2 has no such model, indeed, no model at all.

\section{Conclusions}

Good jobs are experienced by women workers in one company, while in another workplace less than a kilometre away many women experience bad jobs. Both companies operate in the same legislative environment, the same industrial environment, women are minority workers, and both operate in the same local labour market. Managerial commitment, resourcing EEO and reviewing EEO appears to be very different, as is the underlying culture and expectations regarding work. We cannot measure culture or managerial commitment, but on both counts there are substantive dif- 
ferences between the two plants and these come through from the differences in the detail and resources committed to EEO programs and from the different experiences of women workers. At C1 women were consulted, were provided with opportunities for training and career advancement and were given choices about working arrangements. This situation permeated all levels of the organisation and was carried out by line managers. Good jobs were constructed within the organisation through an array of managerial initiatives and cultural practices. At C2, while there were official EEO reports and announced corporate commitment to EEO, however, resources, commitment and implementation of programs by line managers was not present. In C1 women were committed and felt valued, they felt that they had "good" jobs. In C2 women were not consulted or committed, felt marginalised and regarded their jobs as being "bad".

The research highlights how the legislative requirements of EEO program development and EEO reporting does not in itself generate a workplace where EEO conditions are enacted and experienced. There is a need to examine the managerial commitment to EEO programs and the extent to which the experience of women workers matches the ideals of stated EEO programs. Likewise. objective employment conditions provide one indicator of job quality. However, we need to go beneath the veneer of these conditions and examine the experiences of workers and how their jobs are constructed within organisations. Such an examination gives as an insight into what generates "good" work and "bad" work within organisations.

\section{References}

Australian Government (2003): Department of Employment and Workplace Relations, Good Jobs or Bad Jobs, an Australian Policy and Empirical Perspective.

Batt, R./Valcour, P.M. (2003):. Human Resources Practices as Predictors of Work-Family Outcomes and Employee Turnover. In: Industrial Relations 42(2): 189-221.

Belle, F. (2002): Women managers and organisational power. In: Women in Management Review. 17(2):151-156.

Bittman M./Rice, J. (2002): The spectre of overwork: an analysis of trends between 1974 and 1997 using Australian time diaries. In: Labour and Industry, 2(3): 5-25.

Boedel, E. (2003): The provision of formal and informal work-family practices: the relative importance of institutional and resource dependent explanations versus managerial explanations. In: Women in Management Review, 18(12): 7-19.

Burgess, J./Strachan, G (.2005): Integrating work and family responsibilities: policies for lifting women's labour activity rates. In: Just Policy, (35): 5-12.

Christensen, K.E./Staines, G. (1990): Flextime: a viable solution to work-family conflict? In: Journal of Family Issues, (11): 455-76.

Dainty, A./Bagilhole, B./Neale, R. (2001): Male and female perspectives on equality measures for the UK construction sector. In: Women in Management Review, 16(6): 297-304.

Durbin, S. (2006): Gender, Skills and Careerrs in UK Call Centres. In: J. Burgess/ J. Connell (Eds.): Developments in the Call Centre Industry: Analysis, Policy and Challenges. London: Routledge. (forthcoming).

Eason, S.C. (2003): If You Can Use Them: Flexible Policies, Organisational Commitment and Perceived Performance. In: Industrial Relations 42(2): 145-151.

EOWA www.eowa.gov.au, accessed January 2005.

French, E. (2005) In AIRAANZ 2005: Proceedings of the 19th AIRAANZ Conference, Vol. 2 (Eds. Baird, M./Cooper, R./Westcott, M.): 205-212. 
Hakim, K. (1998): Developing a Sociology for the 21st Century: Preference Theory. In: British Journal of Sociology. 49(1): 137-143.

Hyman, J./Summers, J. (2004): Lacking balance? Work-life employment practices in the modern economy. In: Personnel Review, 33: 418.

Hunter, L. (2000): What Determines Job Quality in Nursing Homes? In: Industrial and Labour Relations Review, 53(3):. 463-481.

Lewis, P. (2002) 'Review’ of Work Rich, Work Poor. In: Agenda, 9(3): 267-274.

Liff, S. (1997) Two routes to managing diversity: individual differences or social group characteristics. In: Empoyee Relations, 19(1): 11-26.

MacDermid, S. (2001): 'The Role of Organisational Size and Industry in Job Quality and Work-Family Relationships. In: Journal of Family and Economic Issues, 22(2): 191-216.

Meisenheimer, J. (1998): Service Industry in the Good versus Bad Jobs Debate. In: Monthly Labour Review, 121(2): 22-47.

Pocock, B. (2003): Work-Life Collision. Sydney: Federation Press.

Strachan, G./Burgess, J./Sullivan, A. (2004): Affirmative Action or Managing Diversity - what is the future of equal opportunity in organisations. In: Women in Management Review, 19(4): 196-204.

Townsend, K. (2005): Teams, Control Co-operation and Resistance in New Workplaces. Unpublished $\mathrm{PhD}$ Thesis, Griffith University.

Watts, M. (2002): Workplace Gender Segregation in Australia. Paper presented to the Interdisciplinary Gender Studies Conference Newcastle, NSW, June 2002.

Wagenet, www.gov.au-wagenet. Accessed September 2005.

Whitehouse, G./Frino., B. (2003): Women, wages and industrial agreements. In: Australian Journal of Labour Economics, 6: 579-596.

Whitehouse, G. (2004): Pay equity: 20 years of change and continuity. Women Work and Equity Forum, HREOC http://www.hreoc.gov.au/sex discrimination. 